\title{
Microarray Beads for Identifying Blood Group Single Nucleotide Polymorphisms
}

\author{
Francesca Drago Katerina Karpasitou Francesca Poli \\ Dipartimento di Medicina Rigenerativa - Immunologia dei Trapianti di Organi e Tessuti, Fondazione IRCCS, \\ Ospedale Maggiore Policlinico, Milan, Italy
}

\section{Key Words}

Blood group - SNPs · Micrarray beads .

Single nucleotide polymorphism

\section{Summary}

We have developed a high-throughput system for single nucleotide polymorphism (SNP) genotyping of alleles of diverse blood group systems exploiting Luminex technology. The method uses specific oligonucleotide probes coupled to a specific array of fluorescent microspheres and is designed for typing $J k^{a} / J k^{b}, F y^{a} / F y^{b}, S / s$, $K / k, K p^{a} / K p^{b}, J s^{a} / J s^{b}, C o^{a} / C o^{b}$ and $L u^{a} / L u^{b}$ alleles. Briefly, two multiplex PCR reactions (PCR I and PCR II) according to the laboratory specific needs are set up. PCR I amplifies the alleles tested routinely, namely $J k^{a} / J k^{b}, F y^{a} / F y^{b}$, $S / s$, and $K / k$. PCR II amplifies those alleles that are typed less frequently. Biotinylated PCR products are hybridized in a single multiplex assay with the corresponding probe mixture. After incubation with R-phycoerythrinconjugated streptavidin, the emitted fluorescence is analyzed with Luminex 100 . So far, we have typed more than 2,000 subjects, 493 of whom with multiplex assay, and there have been no discrepancies with the serology results other than null and/or weak phenotypes. The cost of consumables and reagents for typing a single biallelic pair per sample is less than EUR 3.-, not including DNA extraction costs. The capability to perform multiplexed reactions makes the method markedly suitable for mass screening of red blood cell alleles. This genotyping approach represents an important tool in transfusion medicine.

\author{
Schlüsselwörter \\ Blutgruppe - SNPs · Microarray-Beads . \\ Single nucleotide polymorphism
}

\section{Zusammenfassung}

Basierend auf der Luminex-Technologie haben wir ein System mit hohem Durchsatz zur Genotypisierung von "single nucleotide polymorphisms" (SNPs) von Allelen verschiedener Blutgruppensysteme entwickelt. Das Verfahren verwendet spezifische Oligonukleotid-Sonden, die an fluoreszierende "Beads" gekoppelt sind, und eignet sich somit für die Typisierung von Jka/Jkb- Fya/Fyb-, S/s-, K/k-, Kpa/Kpb-, Jsa/Jsb-, Coa/Cob- und Lua/Lub-Allelen. Kurz zusammengefasst besteht das Verfahren aus zwei Multiplex-PCR-Reaktionen (PCR I und PCR II), die entsprechend an die speziellen Bedürfnisse des ausführenden Labors angepasst werden können. PCR I amplifiziert Allele, die routinemäßig getestet werden (Jka/Jkb, Fya/ Fyb, S/s und K/k). PCR II amplifiziert solche Allele, die weniger häufig typisiert werden. Die biotinylierten PCRProdukte werden in einem einzigen Multiplex-Assay mit der korrespondierenden Sondenmixtur hybridisiert. Nach der Inkubation mit R-Phycoerythrin-konjugiertem Streptavidin wird die emittierte Fluoreszenz mithilfe des Luminex 100 analysiert. Bislang haben wir 2000 Personen typisiert, 493 davon mit dem Multiplex-Assay. Dabei gab es abgesehen von Null- und/oder Weak-Phänotypen keine Diskrepanzen zu den serologischen Ergebnissen. Die Kosten der Verbrauchsmaterialien und Reagenzien für die Typisierung eines einzelnen biallelischen Paars pro liegen unter 3,- EUR (DNA-Extraktionskosten nicht eingeschlossen). Auf Grund des Multiplexings ist diese Methode hervorragend für ein Massen-Screening von Erythrozyten-Allelen geeignet. Dieser Genotypisierungsansatz ist stellt ein wichtiges Werkzeug für die Transfusionsmedizin dar.

\section{KARGER}

Fax +497614520714

Information@Karger.de

www.karger.com (c) 2009 S. Karger GmbH, Freiburg

Accessible online at:

www.karger.com/tmh 


\section{Introduction}

During the last decade, there has been increased interest in molecular techniques that support and complement the serologic tests commonly used in immunohematology laboratories [1-5]. The molecular biology approach has revealed particularly helpful in the cases of multi-immunized subjects with autoimmune pathologies, of patients transfused immediately prior to blood group testing, and of transfusion-dependent patients such as those with thalassemia.

Currently, several molecular methods are commercially available. The method choice depends on the specific needs of the laboratory and may be influenced by workload and the necessity for rapid results. Of the new molecular techniques, PCR-SSP is suitable for typing a limited number of samples, while BeadChip, GenomeLab SNPStream, Bloodchip, and other microarray-based platforms are designed for testing larger numbers of samples [1-5].

The multianalyte profiling system (Luminex xMAP; Luminex Corp., Austin, TX, USA) [6, 7] is in widespread use in transfusion centers, especially in those focusing on histocompatibility and immunogenetics. The immunogenetics laboratory at our own institution has used Luminex-based technology since 2003 for HLA typing and antibody specificity identification. On the basis of our experience and due to the needs of the immunohematology laboratory for mass-scale genotyping of red blood cell donors, we have exploited Luminex technology to develop a high-throughput system for single nucleotide polymorphism (SNP) genotyping of alleles of diverse blood group systems.

\section{Principles of the Method}

Luminex technology is a microsphere-based suspension array that can analyze up to 500 different analytes in a single reaction. The fluorescent microspheres are covalently coupled to oligonucleotide probes; the probes are complementary in sequence to the biotin-labeled strand of the PCR product that encompasses the SNP of interest. The microspheres differ in fluorescence intensity, depending on the incorporation of different ratios of red and infrared dyes that emit at 658 and 712 $\mathrm{nm}$ after excitation with a $635-\mathrm{nm}$ red diode laser. A compact flow analyzer (Luminex 100) with two projected laser sources detects the microspheres and quantifies the biomolecular reaction on the microsphere surface.

The method we have developed uses specific oligonucleotide probes coupled to a specific array of fluorescent microspheres and is designed for typing $J k^{a} / J k^{b}, F y^{a} / F y^{b}, S / s, K / k$, $K p^{a} / K p^{b}, J s^{a} / J s^{b}, C o^{a} / C o^{b}$, and $L u^{a} / L u^{b}$ alleles.

\section{Method - General Description}

The method has been described in detail elsewhere [9].

The capture probes [9], complementary in sequence to the biotinylated strand of the target amplicon are synthesized with an amino C-12 modification at the 5 ' end.

Each probe is covalently coupled to a different set of polystyrene carboxylated microspheres by a carbodiimide method in separate reactions $[6,7]$. The bead classifications are purchased internally labeled and ready to couple from Luminex.

When coupled with the capture probes, the beads are stable for at least 6 months.

The method involves an amplification step followed by a direct hybridization procedure. More precisely, we set up 2 multiplex PCR reactions (PCR I and PCR II) according to the laboratory specific needs. PCR I amplifies the alleles tested routinely, namely $J k^{a} / J k^{b}, F y^{a} / F y^{b}, S / s, K / k$, PCR II amplifies those alleles that are typed less frequently.

Each biotinylated PCR amplicon is transferred to 96-well plates (96-well PCR Thermo-Fast ${ }^{\circledR}$ 96, Abgene, Epsom, UK) and denatured at $99{ }^{\circ} \mathrm{C}$. Labeled PCR products are hybridized in a single multiplex assay with the corresponding probe mixture. After three wash steps, the 96-well plate is incubated with R-phycoerythrin-conjugated streptavidin.

Detection and analysis of fluorescence emission are performed using the Luminex 100 analyzer. Fluorescence intensity represents a phycoerythrin signal detected within the counted beads. Median fluorescence intensity (MFI) was collected for a minimum of 100 events per bead classification. Cut-off limits were set at 2 standard deviations from the mean of the positive values of the reference samples. The median fluorescence intensities produced by the Luminex 100 with the corresponding sample code are exported from Luminex data collection software (version 1.7) to a user-friendly MS Excel spreadsheet. The MS Excel spreadsheet is set up to automatically calculate the allelic ratio and to provide the genotype based on previously calculated cut-off values.

Once the DNA is extracted, it is possible to type 96 samples in less than $5 \mathrm{~h}$ (fig. 1). We currently use this method to confirm the results obtained by serology for approximately 200 blood donors/month who have been selected on the basis of their rare phenotype. So far, we have typed more than 2,000 subjects, 493 of whom with multiplex assay, and there have been no discrepancies with the serology results other than null and/or weak phenotypes. As a matter of fact, in the series of subjects tested we have found 1 Colton $^{\text {null }}, 74 \mathrm{Fy}^{\mathrm{b} \text { weak }}, 54 \mathrm{Fy}^{\text {null }}$ phenotypes which would remain undetected using Luminex alone.

\section{Conclusions}

Our multi-year experience with Luminex methodology and the specific needs of the blood bank of our institution, prompted us to develop the microsphere-based suspension 
Fig. 1. Illustration of technical steps using the method described here and processing time (h) up to 96 samples. 1. Genomic DNA extracted from different biological samples is subjected to multiplex PCR where PCR contains a mix of gene-specific primers. 2. Amplified products are made single-stranded by denaturation at $99^{\circ} \mathrm{C}$. 3. Denatured DNA is hybridized in a single multiplex assay. 4. The bead, probe and complementary DNA complex are then labelled with a mixture of phycoerythrin-streptavidin. 5. Detection and analysis of fluorescence emission are performed using the Luminex 100. 6. The median fluorescence intensities produced by the Luminex 100 with the corresponding sample code are exported from $\mathrm{Lu}-$ minex data collection software to a userfriendly MS Excel spreadsheet. The MS Excel spreadsheet calculates the allelic ratio and provides the genotype based on previously calculated cut-off values.
1. Amplification

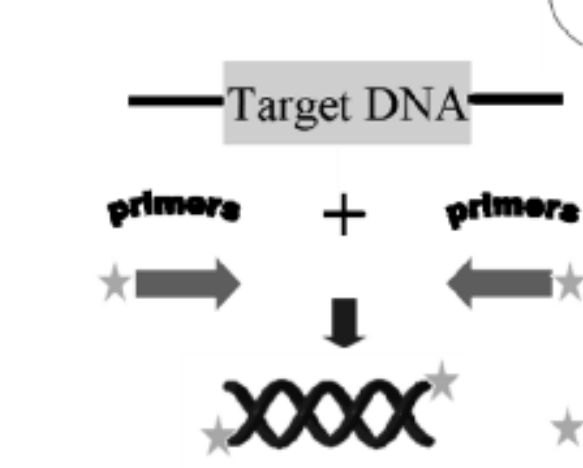

3. Hybridization

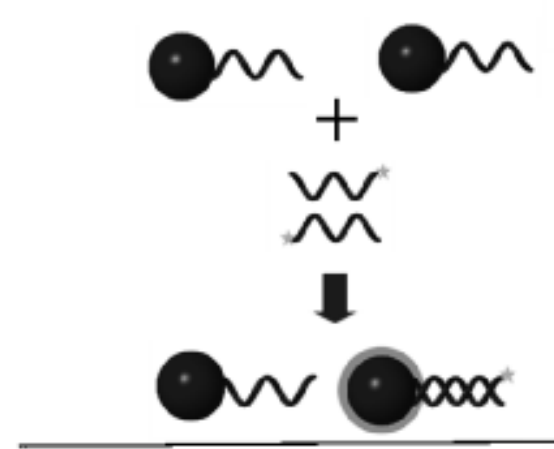

5. Acquisition
2.Denaturation
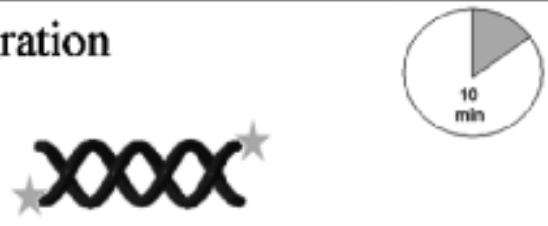

biotin

4. Labeling $99^{\circ} \mathrm{C}$
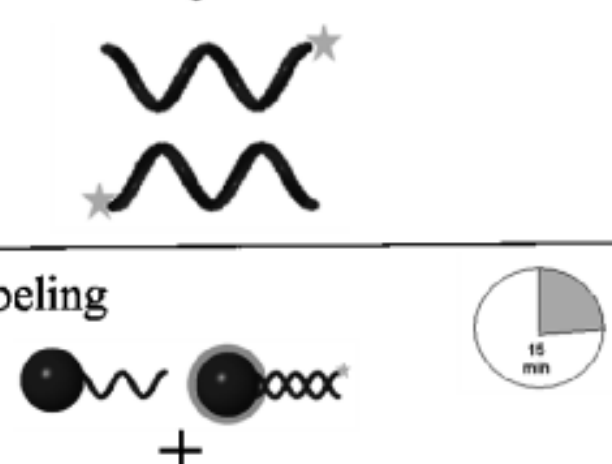

$+$<smiles>[As][Y14]1CCCCC1</smiles>

a

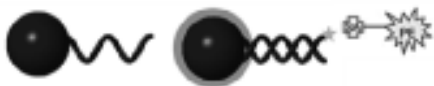

\section{Analysis}
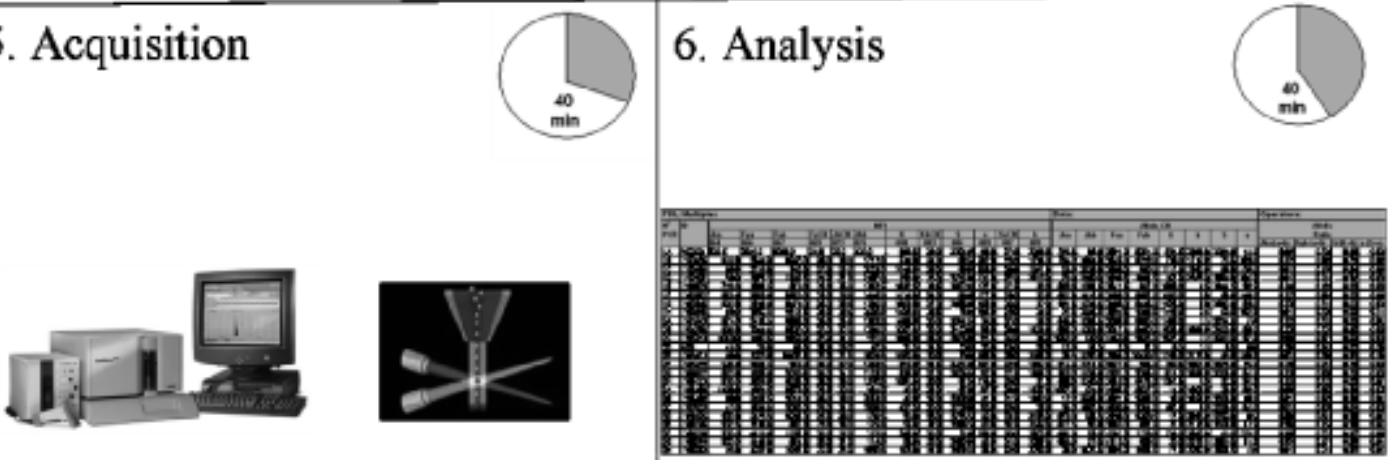

array genotyping system presented here. One of the main advantages of this assay, compared with other high-throughput techniques on the market, is the type of hybridization support. Specifically, the suspension array technique is characterized by fast reaction kinetics, rapid data acquisition, and excellent sensitivity.

Due to the flexibility of the suspension array format, the probe set can be temporarily and reversibly reformulated, depending on the specific requirements of the laboratory, in order to rapidly screen a large number of donors. This is an advantage over microchip technology: if a complete genotype is not required or other alleles are to be tested, new microchips must be designed at an additional cost. In addition, the Luminex approach does not require amplicon purification, and a wide DNA concentration range is allowed, avoiding cumbersome steps.

Furthermore, the recently achieved capability to perform multiplexed reactions represents, compared to earlier versions of the assay $[8,9]$, a major improvement that makes the method markedly more rapid and much more suitable for mass screening of red blood cell alleles.

The cost of consumables and reagents for typing a single biallelic pair per sample is less than EUR 3.-, not including DNA extraction costs. Because Luminex technology is already used in several transfusion centers around the world, most centers will not need to buy expensive instruments or hire expressly trained personnel to implement molecular blood group typing. This, in our opinion, represents anoth- 
er significant advantage with respect to the other platforms where robust bioinformatics [5] is required for result interpretation.

Even if it is possible to type between 1 and 96 samples using the microsphere-based suspension array, the method is cost-effective only when used for a relatively large number of samples. Therefore, it may not be the best choice for laboratories with a small workload. The main drawback to this method is the lack of automation for several phases of the process. For example, sample loading into the trays and the hybridization and wash steps must be carried out manually. In addition, the raw fluorescence data are not automatically downloaded from the Luminex data collector software to the Excel spreadsheet for analysis. Automating these steps, would make blood group genotyping using the Luminex approach even more efficient, competitive, and robust, and would further facilitate the procurement of typed blood units.
In summary, Luminex microarray bead technology has many advantages for SNP genotyping of alleles and is still relatively simple to perform. In the opinion of the authors, this genotyping approach represents an important tool in transfusion medicine and may be an ideal solution for laboratories already familiar with Luminex technology.

\section{Acknowledgment}

The authors are grateful to the personnel of the immunohematology laboratory for the technical support.

\section{Disclosure}

The authors declared no conflict of interest.

\section{References}

1 Hillyer CD, Shaz BH, Winkler AM, Reid M: Integrating molecular technologies for red blood cell typing and compatibility testing into blood centers and transfusion services. Transfus Med Rev 2008; 22:117-132.

2 Wu YY, Csako G: Rapid and/or high-throughput genotyping for human red blood cell, platelet and leukocyte antigens, and forensic applications. Clin Chim Acta 2006;363:165-176.

3 Quill E: Medicine. Blood-matching goes genetic. Science 2008;319:1478-1479.

4 Hashmi G, Shariff T, Zhang Y, Cristobal J, Chau C, Seul M, Vissavajjhala P, Baldwin C, Hue-Roye K, Charles-Pierre D, Lomas-Francis C, Reid ME: Determination of 24 minor red blood cell antigens for more than 2000 blood donors by high-throughput DNA analysis. Transfusion 2007;47:736-747.
Avent ND: Large-scale blood group genotyping: clinical implications. Br J Haematol 2009;144:3-13.

6 Colinas RJ, Bellisario R, Pass KA: Multiplexed genotyping of beta-globin variants from PCR-amplified newborn blood spot DNA by hybridization with allele-specific oligodeoxynucleotides coupled to an array of fluorescent microspheres. Clin Chem 2000;46:996-998.

7 Dunbar SA, Jacobson JW: Application of the luminex LabMAP in rapid screening for mutations in the cystic fibrosis transmembrane conductance regulator gene: A pilot study. Clin Chem 2000;46: 1498-1500.
8 Drago F, Crespiatico L, Espadas de Arias A, Villa A, Karpasitou K, Poli F. Genotyping of the Kidd blood group with allele-specific oligodeoxynucleotides coupled to fluorescent microspheres. Transfus Med 2005;15:499-501.

-9 Karpasitou K, Drago F, Crespiatico L, Paccapelo C, Truglio F, Frison S, Scalamogna M, Poli F: Blood group genotyping for $\mathrm{Jk}(\mathrm{a}) / \mathrm{Jk}(\mathrm{b}), \mathrm{Fy}(\mathrm{a}) / \mathrm{Fy}(\mathrm{b}), \mathrm{S} / \mathrm{s}$, $\mathrm{K} / \mathrm{k}, \mathrm{Kp}(\mathrm{a}) / \mathrm{Kp}(\mathrm{b}), \mathrm{Js}(\mathrm{a}) / \mathrm{Js}(\mathrm{b}), \mathrm{Co}(\mathrm{a}) / \mathrm{Co}(\mathrm{b})$, and $\mathrm{Lu}(\mathrm{a}) / \mathrm{Lu}(\mathrm{b})$ with microarray beads. Transfusion 2008;48:505-512. 